\title{
Seismic analysis of Kunshan Xintiandi super high-rise residential building
}

\author{
Xiaomeng Zhang ${ }^{1}$, Wenting Liu ${ }^{1}$, Qingying ren ${ }^{1}$, Yilun Zhou, Ziao Liu ${ }^{1}$, Xiao yang ${ }^{1}$ \\ ${ }^{1}$ China Architecture Design \& Research Group, Beijing 100044, China)
}

\begin{abstract}
The Kunshan urban investment project includes 1 office tower, 4 high-rise residential buildings and 1 high-rise commercial building.Each monomer shares a large basement chassis, a total of three basement floors. This design is the second phase (4\# residence and corresponding basement). The height of the structure is more than 90 meters, and it is a shear wall structure system. The selection and structure of the structure system are analyzed, and the mechanical performance of the structure is verified through calculation and analysis.
\end{abstract}

\section{Page layout}

\subsection{Project Overview}

The construction site of the project is located in Kunshan City, Jiangsu Province. The proposed site is located on
Qianjin West Road to the north, Louchuang Road to the south and Sichang Road to the east.Zu Chong Road to the west.The project includes one office tower, four residential towers and one commercial tower.Each unit shares the basement, which has three floors in total.This design is 4\# super high-rise residential building and corresponding basement.

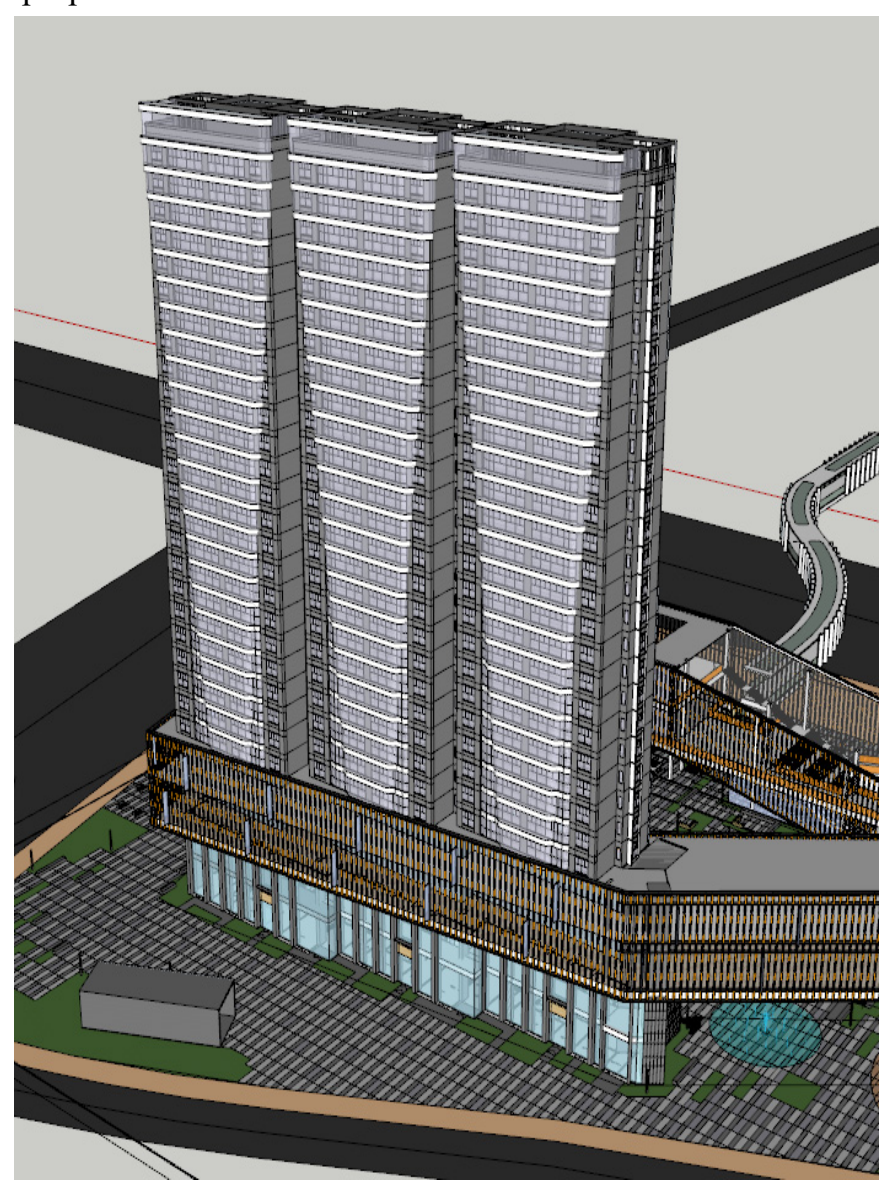

Figure 1. Architectural renderings. 
The design life of the project is 50 years, the safety level of the building structure is grade 2, the fire level of the building structure is grade $1^{[1]}$, and the design level of the foundation foundation is grade a.According to the "Code for Seismic Design of Buildings" (GB50011-2010) (2016 edition) ${ }^{[2]}$, the aseismic group 1 in the area where the project is located, the site category is category IV, the aseismic grade is 7 degrees $0.1 \mathrm{~g}$, and the office area is general fortification category (category c). The load refers to Load code for the design of building structures ${ }^{[3]}$.

\section{Structure selection and classification}

\subsection{Arrangement of high-rise structures}

The project is located in the 7 degree of seismic fortification intensity area, belongs to the standard fortification class building, should be 7 degrees of seismic calculation and seismic measures.

This project tower, the height of the structure is 84.45 meters (27 floors), the main structure of the shear wall structure system. As the main lateral force resistance system, the core tube not only provides resistance to wind load and horizontal earthquake action, but also bears the additional torsion effect caused by the incoincidence of the center of mass and the center of stiffness. The outer frame mainly bears the vertical load, and also bears the role of the second seismic defense line.

\subsection{The setting of structural joints and post-cast belt}

\subsubsection{Shrink post-cast strip}

The plane size of the basement of this project is $118 \mathrm{mx} 470 \mathrm{~m}$, which is a super-long structure.

In order not to affect the use function of the building, this project does not set expansion joints, according to the "Concrete Structure Design Code" [2] (GB50010-2010) using every $30 \mathrm{~m} \sim 40 \mathrm{~m}$ interval to set up shrinkage postpouring belt construction measures, reduce the early concrete shrinkage of the adverse impact on the structure.The width of the post-pouring strip is $0.8 \mathrm{~m}$. Shrinkage post pouring belt on both sides of the members of the concrete pouring for two months, most of the concrete shrinkage after the completion of supplementary pouring. The non-shrinkage concrete with strength grade higher than that of the two side members is used for the supplementary casting of the post cast belt.

The following construction measures and construction measures are adopted in the design to reduce the adverse effects of temperature action and concrete shrinkage in the later period on the structure:
(1) The reinforcement should be as close as possible, and the proportion of the reinforcement should be increased appropriately.

(2) Strengthen the insulation measures of the skirt roof layer and the top floor of the main building, and set the outer insulation layer on the outer wall.

(3) Use of low shrinkage, low hydration heat of cement, appropriate to reduce the amount of cement. Add proper amount of fly ash to concrete.

\section{3 earthquake resistant constructional measure}

This project is a standard fortification building in a 7 degree zone $(0.10 \mathrm{~g})$. As the tower is a composite structure with a high height, its seismic measures will be appropriately improved to ensure the realization of "strong column and weak beam, strong shear and weak bending, strong joint and weak component". In view of this, in the subsequent construction drawing design stage, based on accurate calculation, it is planned to adopt the method of performance design to improve the seismic performance of key components and related structures, appropriately strengthen the structural reinforcement ratio of related components, and rationally deal with the beam-to-column joints to improve the ductility of the structure.Take effective measures to reliably tie the knot with the main body for non-structural components, rear building envelope wall and partition wall.

1) Among them, the seismic grade of the shear wall is 1 , and the bottom strengthening parts and key components shall be strengthened in accordance with the measures of the extra-level member to strengthen the seismic structure.

2) The floor around the large opening should be properly thickened to increase the overall stiffness of the floor and ensure the reliable transfer of horizontal force of the floor. The plate thickness should not be less than $150 \mathrm{~mm}$, and the two-way double-layer reinforcement should be adopted, and the reinforcement ratio should be appropriately increased. The single-layer one-way reinforcement ratio should not be less than $0.3 \%$.

3 ) the use of lightweight filled wall, as far as possible to reduce the weight of the structure, reduce the earthquake action.

\section{Calculation and analysis}

According to the technical code for concrete structures of high-rise buildings (JGJ 3-2010) ${ }^{[1]}$, The $3 \mathrm{~d}$ analysis and design software YJK (version 3.0.3were used for the structural analysis and design ${ }^{[5]}$. The influence of floor cavity is considered in the analysis. The superstructure is embedded in the basement roof of the first floor, The earthquake action and the wind load act in two main directions and the torsional effect under the two-way earthquake action is taken into account. 


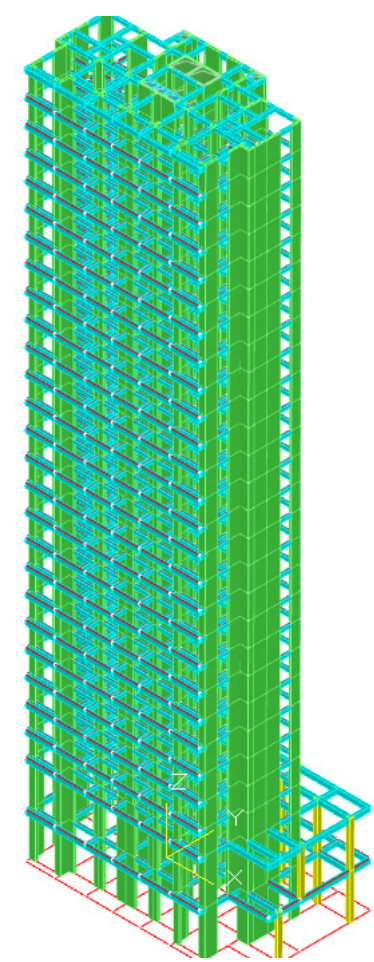

YJK calculation model

Figure 2 finite element analytical model

This project uses YJK as the main tool for structural design and calculation. Table 1 shows the main data of the northwest high-rise building:

Table 1. Two types of software modal cycles and vibration types

\begin{tabular}{|c|c|c|c|}
\hline \multirow{2}{*}{$\begin{array}{c}\text { Vibration } \\
\text { model }\end{array}$} & Period (s) & Vibration & period ratio \\
type & YJK & Y.90] \\
\cline { 2 - 3 } & 2.96 & Y & \multirow{2}{*}{0.61} \\
\hline 2 & 2.598 & $\mathrm{X}$ & \\
\hline 3 & 1.809 & torsion & \\
\hline
\end{tabular}

Table 2. Interlayer displacement Angle comparison of software

\begin{tabular}{|c|c|c|c|}
\hline \multicolumn{2}{|c|}{} & \multicolumn{2}{c|}{ YJK result } \\
\cline { 3 - 4 } \multicolumn{2}{|c|}{} & $\begin{array}{c}\text { Interlayer } \\
\text { displacement } \\
\text { Angle }\end{array}$ & $\begin{array}{c}\text { displacement } \\
\text { ratio }\end{array}$ \\
\hline \multirow{2}{*}{$\begin{array}{c}\text { small } \\
\text { earthqua } \\
\text { kes }\end{array}$} & $\mathrm{X}$ & $1 / 1154$ & 1.06 \\
\cline { 2 - 4 } & $\begin{array}{c}\text { Specificati } \\
\text { on limits }\end{array}$ & $1 / 1028$ & 1.06 \\
\hline
\end{tabular}

Table 3. Seismic force

\begin{tabular}{|c|c|c|c|}
\hline \multirow{7}{*}{ direction } & $\begin{array}{c}\text { The bottom } \\
\text { shear of the } \\
\text { super tall } \\
\text { building } \\
(\mathrm{kN})\end{array}$ & $\begin{array}{c}\text { Minimum } \\
\text { shear } \\
\text { weight } \\
\text { ratio for } \\
\text { floors }\end{array}$ & allowable \\
value \\
\hline
\end{tabular}

\begin{tabular}{|c|l|l|l|}
\hline $\mathrm{X}$ & 4415.1 & $4.70 \%$ & $2.40 \%$ \\
\hline $\mathrm{Y}$ & 3651.9 & $5.10 \%$ & $2.40 \%$ \\
\hline
\end{tabular}

After analysis, the overall design index is good, the first and second period is translational period, the third period is torsional period, the stiffness of the two directions of the structure is not much different, and the ratio of the first torsional period to the first translational period of the structure is less than 0.85 , which meets the requirements of the code. The shear weight ratio of the two directions at the bottom of the structure meets the requirements of not less than $1.2 \%$ in the "Anti-Gauge". Both directions were less than the standard limit of $1 / 1000$.The calculation models of the two software are basically consistent and the dynamic characteristics of the structure are basically consistent. The natural vibration period, displacement Angle between layers, displacement ratio and other indexes of the structure are similar, and all of them are in a reasonable range, which meet the requirements of the current code.

\section{Conclusion}

Through the reasonable selection of the structural system and the analysis by YJK software under the action of small earthquakes, all the design indexes obtained can meet the requirements of anti-gauge. Because the structure for reinforced concrete shear wall high-rise structure, in order to improve its seismic ability and ductility, through reasonable layout, the formation of the space overall stress system, and take some local strengthening measures, make the structure in the earthquake has a good seismic performance. 


\section{References}

1. Technical specification for concrete structures of tall building JGJ 3 -2010[s] Beijing China building industry press

2. Code for seismic design of buildings GB 500112010 [s] Beijing China building industry press

3. Load code for the design of building structures GB 5 0092012[s] Beijing China building industry press

4. Code for design of concrete structures GB500102010: GB 50010 - 2011［S］Beijing China building industry press, 2011.

5. Xu PF,Fu XY,Wang CK Structural design of comple $\mathrm{x}$ high-rise buildings $\quad$..Beijing China building industry press 